\title{
Effective Nature-Like Structural Thermal Insulation and Acoustic Composites Based on Technogenic Raw Materials
}

\author{
Lesovik V.S. \\ Construction Engineering Institute \\ Belgorod State Technological University named \\ V.G. Shoukhov \\ Belgorod, Russia \\ naukavs@mail.ru \\ Volodchenko A.A. \\ Construction Engineering Institute \\ Belgorod State Technological University named \\ V.G. Shoukhov \\ Belgorod, Russia \\ alex-0904@mail.ru \\ Chernysheva N.V. \\ Construction Engineering Institute \\ Belgorod State Technological University named \\ V.G. Shoukhov \\ Belgorod, Russia \\ chernysheva56@rambler.ru
}

\author{
Puchka O.V. \\ Institute of Power engineering, Information technologies \\ and Management systems \\ Belgorod State Technological University named \\ V.G. Shoukhov \\ Belgorod, Russia \\ oleg8a@mail.ru
}

Glagolev E.S.

Construction Engineering Institute

Belgorod State Technological University named

V.G. Shoukhov

Belgorod, Russia

sk31.es@gmail.com

Lashina I.V.

Construction Engineering Institute

Belgorod State Technological University named

V.G. Shoukhov

Belgorod, Russia

lashina.irishka@yandex.ru

\begin{abstract}
One of the most important problems of our time is the creation of fundamentally new, technological solutions in the field of energy saving, rational nature management, creation of environmentally friendly production of composite building materials, which corresponds to the current trends in the development of "nature-like" technologies that can not disrupt the ecology and the environment; maintain a balance between biosphere "and" technosphere". This paper shows that due to the use of natural and technogenic raw materials of various genesis, it is possible to create nature-like building composites of various functional purposes (structural heat insulating, heat insulating, acoustic, etc.). These composites are supposed to protect people from the effects of the environment, ensuring them a comfortable and safe existence: a favorable acoustic and thermal-moisture regime, environmental safety, and other comfort systems.
\end{abstract}

Keywords—geonics (geomimetics), technological raw materials, construction and insulation composites, foam glass, acoustic composites, finishing materials, aluminosilicate raw materials

\section{INTRODUCTION}

Currently, the protection of buildings and structures from noise aggression becomes very relevant. A number of scientific papers are devoted to the problem of noise control and the role of acoustic materials in creating favorable sanitary and hygienic conditions in buildings and constructions with noisy activities, which deal with theoretical and methodological issues devoted to the study of the pattern of noise propagation in open spaces and indoors. According to the rules for the operation of buildings and structures, in addition to good sound-proofing and sound-absorbing ability, acoustic materials must also meet other requirements decorative, mechanical properties, etc.

To create effective acoustic materials, it is necessary to search for new types of raw materials, which are made by geological processes to obtain specific building materials, as well as the introduction of environmentally friendly, wasteless, energy-saving technologies. The transdisciplinary scientific direction of geonics (geomimetics), the idea of which is to apply knowledge of natural processes, is aimed at solving these problems.

\section{Methods And MATERIALS}

The raw materials used to create the composite were quartz sand from the Belgorod deposit, anhydrous crystalline soda of the Pikalevsky Alumina Manufactory GOST 10689-75, dolomite from the Melekhovo - Fedotovsky (Kovrov) deposit, sodium sulfate from the Balakovo artificial fiber factory (Balakovo, Saratov region), colemanite (Turkey).

Foaming mixture for samples of foam glass was prepared 
by mixing the raw materials in the right proportions, which were poured into pre-prepared forms and placed in a furnace for foaming according to a previously developed temperaturetime mode at a maximum foaming temperature of $870^{\circ} \mathrm{C}$.

Portland cement, GOST 31108-2003, was used as a binding component for creating finishing composites based on eolian, eluvium and diluvium clay rocks of the Quaternary age of the Kursk Magnetic Anomaly deposits. Belgorodstroymaterialy JSC GOST 9179-77 applied quicklime. The mixture for clay-based finishing composites, included a pre-prepared binder (pre-milled clay and a binder component), then mixed with the base rock and also moistened with water. After molding, the samples were placed in a steam chamber and were subjected to heat and humidity treatment at a temperature of $90-95^{\circ} \mathrm{C}$ according to the mode: 1.5 h. +9 h. +1.5 h.

To determine the particle size distribution of the materials, the MicroSizer 201 was used, which allows determining particles with sizes from 0.2 to 600 microns. For the study of the mineralogical composition of raw materials and synthesized tumors used the method of X-ray phase analysis. Studies were performed on the X-ray diffractometer model ARL X'TRA. Thermo Fisher Scientific.

In addition to X-ray phase analysis, to identify the products of tumors and the mineral composition, DifferentialThermal Analysis was used. The studies were carried out on a device - Derivatograph Q - 1500 D. A microscope MIRA 3 LM was used for scanning electron microscopy (SEM).

\section{RESULTS}

The implementation of theoretical concepts and a systematic approach to solve problems within the framework of geonics (geomimetics), allowed us to develop a methodological basis for creating effective building composites [1-3]. So, today, scientists are faced with the task of developing composite materials with improved heat engineering and acoustic parameters [4-7]. Comparative characteristics of the most common thermal insulation and acoustic materials indicate that the use of foam glass based materials is the most promising in terms of the complex of properties [8-10]. The natural analogue of this material is volcanic porous rocks, which has high physical and mechanical properties. For example, foam glass with a density of $150 \mathrm{~kg} / \mathrm{m} 3$ has a compressive strength of $0.5 \mathrm{MPa}$, and volcanic porous rocks with the same density have a strength of 5-6 times more.

From the point of view of geonics (geomimetics), were analyzed the causes of high thermal and sound insulation characteristics of volcanic rocks (pumice and tuff), and it was found that the presence of a double pore system in pumice is at the macro level, with a pore size of $0.5-2 \mathrm{~mm}$, and size, located in the walls of the pores of the macro level contributes to a higher value of sound absorption than tuff with a solid surface (which acts as an effective sound insulation material) (Table 1).
TABLE I. SOUND ABSORPTION COEFFICIENTS OF THE STUDIED MATERIALS

\begin{tabular}{|c|c|c|c|c|c|c|}
\hline \multirow{2}{*}{ Material } & \multicolumn{6}{|c|}{ Sound absorption coeficient, $\boldsymbol{\alpha}$} \\
\cline { 2 - 7 } & $\mathbf{1 2 5}$ & $\mathbf{2 5 0}$ & $\mathbf{5 0 0}$ & $\mathbf{1 0 0 0}$ & $\mathbf{2 0 0 0}$ & $\mathbf{4 0 0 0}$ \\
\hline Pumice & 0.14 & 0.19 & 0.32 & 0.43 & 0.48 & 0.50 \\
\hline Tuff & 0.10 & 0.12 & 0.18 & 0.22 & 0.31 & 0.35 \\
\hline
\end{tabular}

The predominance of the cryptocrystalline structure in materials retains high thermal, acoustic insulation and strength characteristics. Crystalline inclusions in the structures of these minerals are found both in interporous partitions and on the inner surface of pores (Fig. 1, 2).
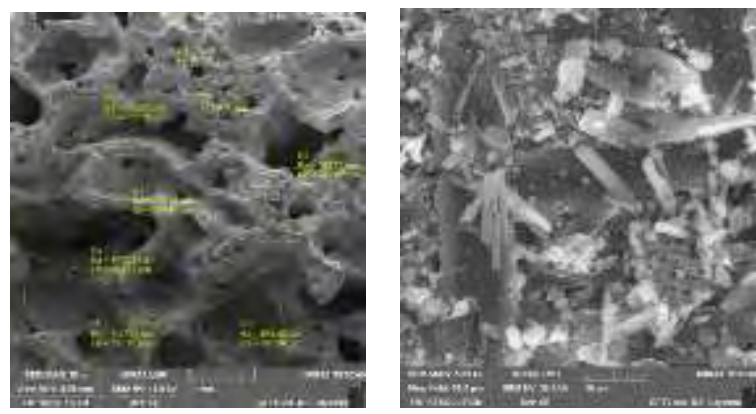

Fig. 1. The structure of pumice.
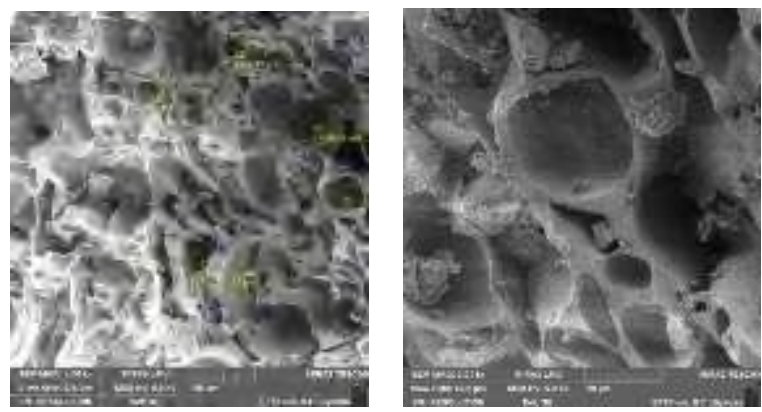

Fig. 2. The structure of pumice.

As a result of studies of the physico-technical and structural characteristics of volcanic pumice and tuff, it was found that the efficiency of sound absorption of airborne noise in these materials depends on the structure of interstitial partitions.

Thus, the structure of pumice and tuff can be thought of as an amorphous matrix stuffed with crystalline inclusions. Therefore, to obtain materials with enhanced performance characteristics, it is necessary to create an amorphouscrystalline structure of the material, which due to crystalline inclusions would have increased strength, and due to a porous amorphous or cryptocrystalline matrix, would retain high thermal and sound insulating characteristics, preventing the formation of a solid crystalline frame which increases the heat and sound transmission in the material.

The established patterns were used in the development of effective sound insulation and sound-absorbing acoustic 
materials, based on foam glass, as the closest anthropogenic analogue of natural tuff and pumice.

Microstructure studies were carried out to create sound insulation materials (Fig. 3.4). It was found that the material obtained using $4 \%$ boron-containing raw materials (Composition No. 1), has no obvious crystalline inclusions.
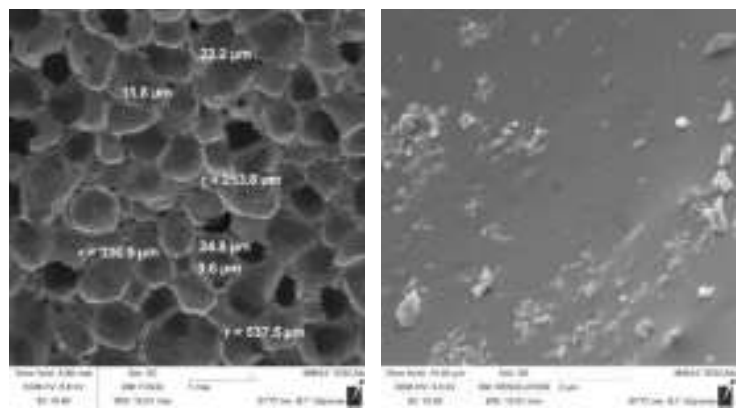

Fig. 3. The microstructure of sound-proof material obtained using $4 \%$ boroncontaining raw materials (foaming temperature $850-870^{\circ} \mathrm{C}$.

The glass composite obtained using $6 \%$ boron-containing raw materials (composition No. 2) is distinguished by a more uniform fine-pore structure and the presence of columnar crystals (Fig. 4) on the inner surface of the pore and the interporous septum, which form the reinforcing framework of the material.
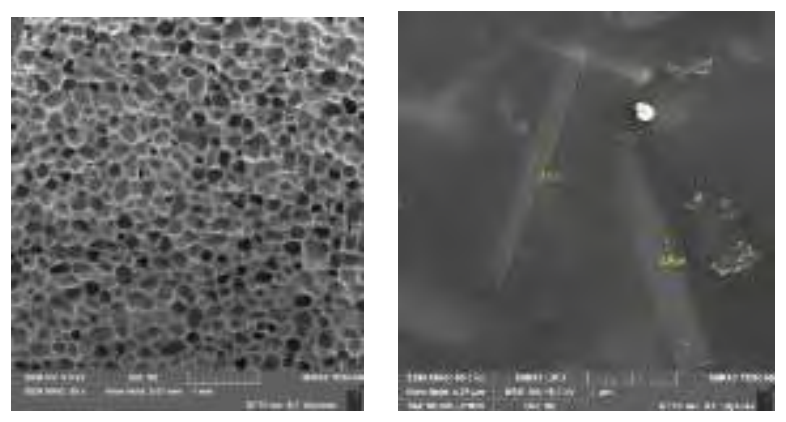

Fig. 4. The microstructure of sound-proof materials obtained using $6 \%$ boron-containing raw materials (foaming temperature $800-820^{\circ} \mathrm{C}$ ).

By increasing the amount of added boron-containing raw materials, the temperature-time mode of foaming was optimized, which made it possible to reduce the foaming temperature by $6 \%$.

As a result of the analysis of the radiographs' peaks, it was found that the sample obtained on the developed composition No. $3(4 \% \mathrm{~K})$, foamed at a temperature of $850-870{ }^{\circ} \mathrm{C}$, differs from the sample of composition No. $2(6 \% \mathrm{~K})$, obtained at $800-820^{\circ} \mathrm{C}$, with a higher content of the crystalline phase (3.4\% versus $13.9 \%$ ), represented by silicon oxide $\alpha-\mathrm{SiO} 2$ (d / n, A: $4.25 ; 3.35 ; 2.45 ; 1.81 ; 1.62)$ and feldspars in the form of $\beta$ wollastonite $\mathrm{CaO} \mathrm{SiO} 2$ (d / n, A: 3.31; 2.95; 2.46; 1.81). The evaluation was made of the physico-technical parameters of the glass-ceramic material for sound-proof purposes (SKZI) (Table 2).
TABLE II. MAIN OPERATIONAL PROPERTIES OF SKZI

\begin{tabular}{|c|c|c|c|c|c|c|c|c|}
\hline Content & $\begin{array}{c}\mathbf{T}_{\mathbf{v s}}, \\
{ }^{\circ} \mathbf{C}\end{array}$ & $\begin{array}{c}\boldsymbol{\rho}_{\mathbf{c p}}, \\
\mathbf{k g} / \mathbf{m}^{3}\end{array}$ & $\begin{array}{c}\mathbf{R}_{\mathbf{c}}, \\
\mathbf{M P a}\end{array}$ & $\begin{array}{c}\text { Isolation } \\
\text { idex, } \mathbf{d B}\end{array}$ & $\begin{array}{c}\text { Sound } \\
\text { absorption }\end{array}$ & $\begin{array}{c}\boldsymbol{\gamma}, \\
\mathbf{V t} \mathbf{m} \\
\mathbf{K}\end{array}$ & $\mathbf{K}_{\mathbf{v s p} .}$ & $\begin{array}{c}\mathbf{W}, \\
\mathbf{\%}\end{array}$ \\
\hline No. 1 & $\begin{array}{c}850- \\
870\end{array}$ & 130 & 1.2 & $9-10$ & 0.17 & $\begin{array}{c}0.045- \\
0.050\end{array}$ & 4.6 & $<5$ \\
\hline No. 2 & $\begin{array}{c}800- \\
820\end{array}$ & 160 & 3.1 & $14-16$ & 0.16 & $\begin{array}{c}0.055- \\
0.060\end{array}$ & 3.9 & $<5$ \\
\hline
\end{tabular}

When looking at the tab. 3 we can say that with sufficiently close values of density and thermal conductivity, the developed materials surpass the control sample in sound insulation and strength characteristics, in the sound insulation index they surpass by $25-70 \%$ and increase the strength by 3.3 times.

Thus, at the first stage of the study, a soundproof material was developed. The combination of open pores on the surface of the material, closed pores inside, makes it possible to use both heat insulating and reflection-reducing sound simultaneously [11].

Glass composite soundproof destination is recommended to protect buildings and industrial buildings from external influences, to isolate process piping, flange connections and valves with positive and negative working environment temperatures, process equipment and production piping with high demands on cleanliness of indoor air.

To obtain sound-absorbing materials effective in a wide frequency range, it is necessary to create a multitrack open dead-end porosity in the bulk of the material. For this purpose, we developed a complex blowing agent consisting of a multifunctional additive and carbon black.

As a result of optimizing the amount of blowing agent (the criterion for selecting the optimal compositions was the sound absorption coefficient), the compositions were determined (Table 3 ) with a blowing agent content of $0.25 \%$ and $0.3 \%$.

TABLE III. MAIN OPERATIONAL PROPERTIES OF THE MATERIAL

\begin{tabular}{|c|c|c|c|c|c|}
\hline \multicolumn{2}{|c|}{\begin{tabular}{c} 
Blowing agent \\
\multicolumn{2}{|c|}{$\begin{array}{c}\text { Colemanite // Carbon, \% } \\
\text { SKZI }\end{array}$}
\end{tabular}} & Caux. & $\begin{array}{c}\mathbf{P}_{\text {aver, }} \\
\mathbf{k g} / \mathbf{m 3}\end{array}$ & $\begin{array}{c}\mathbf{W}, \\
\mathbf{\%}\end{array}$ & $\begin{array}{c}\text { Sound abs-n } \\
\text { coefficient }\end{array}$ \\
\hline \multirow{4}{*}{4.5} & - & 3.9 & 310 & 23 & 0.2 \\
\cline { 2 - 6 } & 0.1 & 3.7 & 285 & 24 & 0.28 \\
\cline { 2 - 6 } & 0.2 & 4.0 & 255 & 27 & 0.39 \\
\cline { 2 - 6 } & 0.25 & 4.2 & 230 & 28 & 0.67 \\
\cline { 2 - 6 } & 0.3 & 4.7 & 205 & 35 & 0.70 \\
\cline { 2 - 6 } & 0.35 & 4.7 & 180 & 45 & 0.48 \\
\cline { 2 - 5 } & 0.4 & 4.9 & 190 & 75 & 0.35 \\
\hline
\end{tabular}

The most pronounced sound absorption coefficient was observed for samples obtained by introducing a complex blowing agent into the foaming mixture at a ratio of $4.5 \% \mathrm{~K} / /$ $0.25 \% \mathrm{C}$ to $4.5 \% \mathrm{~K} / / 0.30 \% \mathrm{C}$ (Fig. 5). 


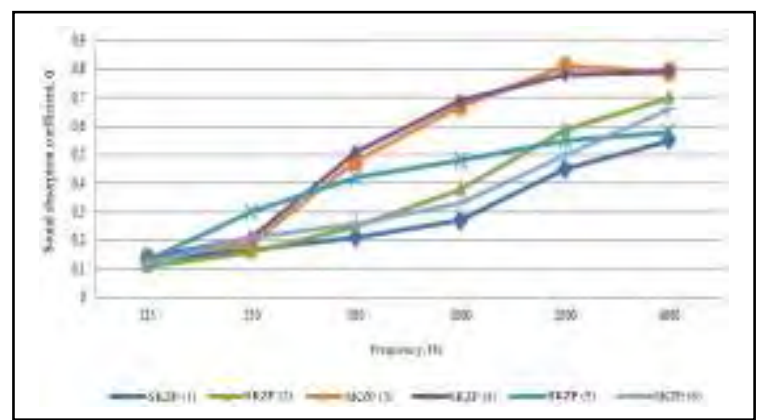

Fig. 5. Sound absorption samples of VCCU obtained on the basis of a complex blowing agent.

Analysis of micrographs (Fig. 6) showed that the introduction of a complex blowing agent allows controlling the structure formation processes. It allows to change type and size of pores on the surface of the material and the character of the inner surface of pores, which made it possible to obtain a sound-absorbing material with a multitrack open dead-end structure capable of absorbing sound waves in a wide frequency range.
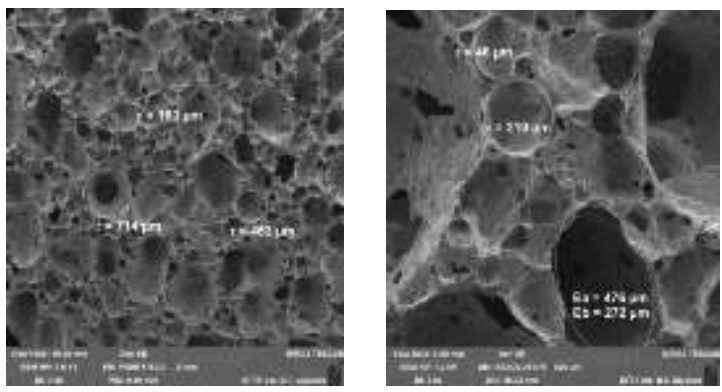

Fig. 6. Micrograph of a sample foamed on a complex blowing agent (colemanite // technical carbon, \%: $4.5 / / 0.25$ ).

As a result of the experimental and theoretical materials' analysis, the dependence of sound-absorbing properties on the structure of the material was found, and it was established that the main mechanism of absorption of sound energy is concentrated in dead-end branches of the structural framework. The combination of open pores of a developed material surface allows the material to be widely used as absorbing and dissipating sound energy. Considering the high sound-absorbing characteristics and the large color range, the developed decorative-acoustic materials are recommended to be used in concert halls, theaters, cinemas, auditoriums, conference halls, on radio, television and film studios.

To create highly efficient finishing materials with good sound-absorbing characteristics, it is also possible to use clay rocks as a raw material. Structural and textural features of the structure of natural clay minerals [12-14], can impede the penetration of sound streams, and as a result, improve the sound-absorbing properties of composites based on them.

The study of kaolinite as an example under an electron microscope showed that the mineral consists of layers of flat nanocrystals stacked like stacks of coins. The photomicrographs of kaolinite are presented in Figure 7. The lamellar crystals of the mineral, whose thickness is $37-45 \mathrm{~nm}$, are clearly visible. The distance between the plates is about 1 nm.
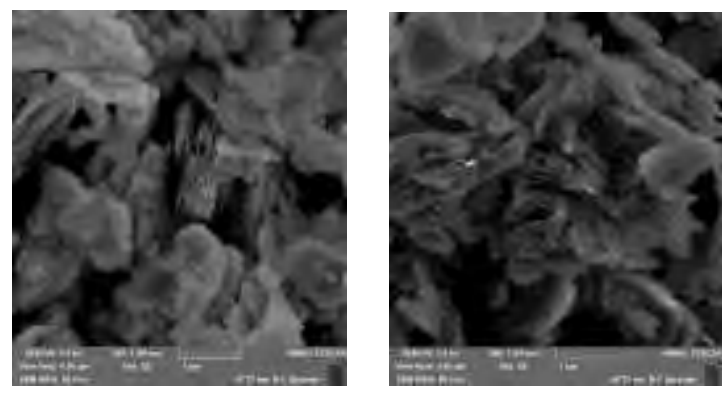

Fig. 7. Kaolinite microstructure.

The material composition of unconventional clay rocks is of particular interest: the presence of thermodynamically unstable compounds helps to reduce the energy intensity of obtaining efficient building composites of the new generation. Due to the use of such raw materials in the production of acoustic materials, it is possible to switch from traditional raw materials to obtain composite binder based on natural nanodispersed raw materials, which will accelerate the synthesis of tumors, change their morphology, optimize the microstructure of the cementing compound and, accordingly, improve the physico-mechanical properties of products [1517]. On the territory of the Kursk Magnetic Anomaly (CMA), the most common are eolian, eluvium and diluvium clay rocks of a quaternary age. A significant proportion of these rocks do not meet the regulatory requirements for raw materials for the production of cement and ceramic materials, but due to their material composition it can be used to produce silicate materials. Therefore, these rocks were chosen as the object of study.

The externally investigated material is a crumbly rock; the color range has a brown-reddish color. Clay rocks number 1 and number 2 are characterized by plasticity numbers 7.5 and 11. Clay rock number 3 is 14 . Clay rocks are represented by mixed-layer formations, X-ray amorphous phase, and small amounts of hydro mica, $\mathrm{Ca} 2+$ montmorillonite and kaolinite. Samples for research were obtained by injection molding. The amount of quicklime was $5-25 \%$ by weight of the dry mixture. The humidity of the raw mix depended on its composition (30$40 \%$ ). In order to increase the efficiency of the composites obtained, the experiment was carried out with the addition of polypropylene fiber in the raw material mixture, for $1 \%$. The results of the experiment are shown in the Fig. 8.

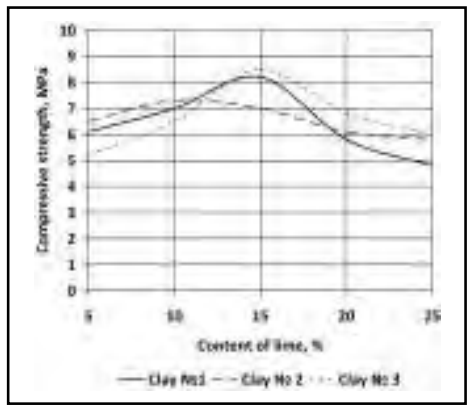

Fig. 8. Compressive strength of samples depending on the content of the binder, with a fiber content of $1 \%$ 
The microstructure of the sample based on clay No. 1, with a fiber content of $1 \%$ and 15 wt. $\% \mathrm{CaO}$ was examined on a scanning electron microscope (Fig. 9).
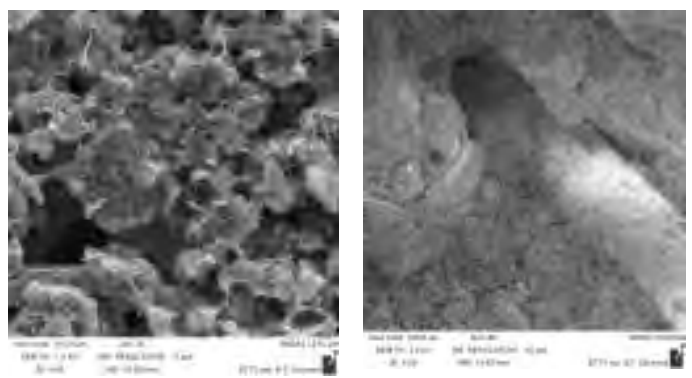

Fig. 9. The microstructure of the sample with a fiber content of $1 \%$ and 15 wt. $\% \mathrm{CaO}$.

The structure of the resulting composites due to the high humidity of the raw mix is loose. There is a large number of pores. The introduction of fiber in the amount of up to $1 \%$ allows to significantly increase the performance of composites, which is explained by the tight adhesion of the fiber and the binder. Thus, the use of reinforcing fiber in the composition of building composites makes it possible to obtain composites with higher performance characteristics. The choice of the type of reinforcing fiber will depend on what characteristics need to be improved. However, in order to reduce the weight of products using a metal fiber is impractical.

Studies have shown that because of such raw materials, nonautoclaved silicate finishing materials can be obtained with high physico-mechanical properties.

\section{CONCLUSION}

Conducted research has resulted in a wide range of effective nature-like structural thermal insulation and acoustic composites based on technogenic raw materials. This is the traditional thermal insulation of industrial and residential fencing constructions built in the anomalous conditions of the North and the Arctic), heat and sound insulation of utilities, heating, oil and gas pipelines. Noise insulation of exterior and interior walls and floors of buildings located near busy roads, railways, airports, and in cases where the noise source is inside the room. It is the different nature of the material structure that predetermines their functional use.

Thus, the theoretical aspects of improving the efficiency of inorganic acoustic materials using the boron-containing component and optimizing the technological conditions of formation of the structure of the foam glass have been developed, which makes it possible to obtain sound-insulating and sound-absorbing acoustic building materials. Proposed effective finishing materials based on non-traditional for the construction industry clay rocks with good sound-absorbing characteristics, due to the structural and textural features of the structure of clay minerals.

\section{Acknowledgment}

The reported study was funded by RFBR according to the research project No. 18-03-00352.

\section{References}

[1] R.S. Fediuk, Y.G. Yevdokimova, A.K. Smoliakov, N.Y. Stoyushko and V.S. Lesovik "Use of geonics scientific positions for designing of building composites for protective (fortification) structures", IOP Conference Series: Materials Science and Engineering, vol. 221(1), pp. 012011, 2017.

[2] M.Yu. Elistratkin and M.I.Kozhukhova, "Analysis of the factors of increasing the strength of the non-autoclave aerated concrete", Construction Materials and Products, vol. 1, Iss. 1, pp. 59-68, 2018.

[3] T.V. Dmitrieva, V.V. Strokova and A.A.Bezrodnykh, "Influence of the genetic features of soils on the properties of soil-concretes on their basis", Construction Materials and Products, vol. 1, Iss. 1, pp. 69-77, 2018.

[4] J. Bai, X. Yang, Sh. Xu, W. Jing, J. Yang, "Preparation of foam glass from waste glass and fly ash", Materials Letters,136, pp. 52-54, 2014.

[5] L.A. Suleymanova, K.A. Kara, K.A. Suleymanov, A.V. Pyrvu, D.D. Netsvet and N.P. Lukuttsova, "The topology of the dispersed phase in gas concrete", Middle East Journal of Scientific Research, vol. 18(10), pp. 1492-1498, 2013.

[6] Longwei $\mathrm{Hu}$, Fangming $\mathrm{Bu}$, Fenglu Guo and Zimeng Zhang, "Construction method of foam glass thermal insulation material in sloping roof', IOP Conference Series: Earth and Environmental Science, 61, p. 012122, 2017.

[7] H. Wang, K. Feng and Q. Sun, "Effect of calcium carbonate on the preparation of glass ceramic foams from water-quenched titaniumbearing blast furnace slag and waste glass", Advances in Applied Ceramics, 117 (5), pp.1-7, 2018

[8] H. Shi, K. Feng, H. Wang, Ch.-H. Chen and H. Zhou, "Influence of aluminium nitride as a foaming agent on the preparation of foam glassceramics from high-titanium blast furnace slag", International Journal of Minerals, Metallurgy, and Materials, 23(5), pp. 595-600, 2016.

[9] Ch. Chen, K. Feng, Yu Zhou and H. Zhou, "Effect of sintering temperature on the microstructure and properties of foamed glassceramics prepared from high-titanium blast furnace slag and waste glass", International Journal of Minerals, Metallurgy, and Materials, 24(8), pp:931-936, 2017.

[10] Yu-L. Wei, Sh.-H. Cheng, K.-T. Ou, P.-J. Kuo, T.-H. Chung and X.-Q., "Effect of Calcium Compounds on Lightweight Aggregates Prepared by Firing a Mixture of Coal Fly Ash and Waste Glass", Ceramics International, 43(17), pp. 15573-15579, 2017.

[11] L.V. Sapacheva and S.YU. Goreglyad, "Foam Glass for green building in Russia", Construction Materials, No 7, pp. 68-70, 2017.

[12] Ali Olad , "Polymer / Clay Nanocomposites", Advances in Diverse Industrial Applications of Nanocomposites, InTech, pp. 113-138, 2011.

[13] P. Kiliaris and C.D. Papaspyrides, "Polymer layered silicate (clay) nanocomposites: An overview of flame retardancy", Progress in Polymer Science, 35, pp. 902-958, 2010.

[14] A. Elamri, K. Abid, S. Dhouib and F. Sakli, "Morphological and Mechanical Properties of Nanoclay Coated Fabric", American Journal of Nano Research and Application. Special Issue: Nanocomposites Coating and Manufacturing, 3(4-1), pp. 17-24, 2015.

[15] A.A. Volodchenko, V.S. Lesovik, A.N. Volodchenko, E.S. Glagolev, L.H. Zagorodnjuk, Y.V. Pukharenko, "Composite performance improvement based on non-conventional natural and technogenic raw materials", Int. J. of Pharm. and Techn., vol. 8(3), pp. 18856-18867, 2016.

[16] D. Klimesch and A. Ray, "Evaluation of phases in a hydrothermally treated $\mathrm{CaO}-\mathrm{SiO} 2-\mathrm{H} 2 \mathrm{O}$ system", Journal of Thermal Analysis and Calorimetry, 70(3), pp. 995-1003, 2002.

[17] S Bernstein, Thomas Karl Fehr, "The formation of $1.13 \mathrm{~nm}$ tobermorite under hydrothermal conditions: 1 . The influence of quartz grain size within the system $\mathrm{CaO}-\mathrm{SiO} 2-\mathrm{D} 2 \mathrm{O}$ ", Progress in Crystal Growth and Characterization of Materials, 58 (2-3), 2012, pp: 84-91. 
